ВАСИЛЬЕВ Игорь Владимирович - кандидат технических наук, военнослужащий (г. Москва; vasigo74@yandex.ru)

\title{
ТРУДОВЫЕ РЕСУРСЫ РОССИИ В ЗЕРКАЛЕ ДЕМОГРАФИЧЕСКОЙ СИТУАЦИИ
}

Аннотация. В статье рассматриваются проблемы, сдерживающие развитие трудовых ресурсов в контексте демографической ситуации. Автор анализирует прогнозы и динамику народонаселения страны, формулирует предложения по совершенствованию государственной политики оздоровления демографической ситуации и наращивания трудовых ресурсов в Российской Федерации.

Ключевые слова: трудовые ресурсы, демографическая политика, семья, рождаемость, смертность, демографический кризис, численность населения, возрастные группы

Д емографическая ситуация в России в последнее время стала одной из актуальных социально-экономических проблем по причине ее тесной связи со снижением уровня трудовых ресурсов. Ухудшение демографической ситуации влечет за собой упадок численности трудоспособного населения, а также порождает многие экономические и геополитические опасности. Системное решение проблемы выбывания трудовых ресурсов лежит в плоскости улучшения демографической ситуации: между двумя последними переписями населения страна потеряла 2,3 млн чел. ${ }^{1}$ Особую озабоченность вызывает тенденция убыли населения в трудоспособном возрасте.

В последнее десятилетие Россия вступила в период снижения численности трудоспособного населения. Сложившуюся ситуацию можно назвать очередной поворотной точкой новейшей демографической истории России. Она вызвана, как нам представляется, исчерпанием демографического дивиденда.

В 90-е гг. ХХ столетия, когда кривая рождаемости опустилась ниже кривой смертности, трудоспособное население России не уменьшилось, а даже выросло. Такова была комбинация разбалансированных еше со времен Великой Отечественной войны поколений. Однако уже с 2007 г. начался период быстрого сокращения численности трудоспособного населения. Этот процесс продолжается и становится одним из ведущих факторов, сдерживающих развитие России.

Объективная статистика свидетельствует о сокращении трудовых ресурсов и старении нации. Однако не все политологи, социологи и этнографы видят в этом общественно значимую проблему. Исследователей проблем трудовых ресурсов условно можно разделить на скептиков и прагматиков.

Первые считают, что демографические процессы, связанные с рождением и смертностью, не следует контролировать. В демографии контролю подлежат лишь миграционные процессы. Они склонны думать и говорить, что нужно либо вообще не заниматься управлением демографическими процессами, либо контролировать только миграционные процессы. Некоторые специалисты считают, что рождение детей - личное дело каждого гражданина и призывы к изменению «демографического поведения» нарушают права человека.

Прагматики призывают государство и общество активно влиять на демографическую ситуацию и стимулировать рождаемость путем государственных мер поддержания семьи. Они выступают инициаторами разработки методологи-

\footnotetext{
${ }^{1}$ Сайт Федеральной службы государственной статистики. Доступ: http://gks.ru (проверено
} 11.09.2021). 
ческих подходов и практических рекомендаций, которые показывают связь между депопуляцией и проблемами уровня и качества жизни. Точка зрения прагматиков с годами становится все более весомой и популярной в научном сообществе и в российском обществе в целом.

Реализация многочисленных национальных проектов и стратегий развития Российской Федерации требует дополнительных трудовых ресурсов не только в гражданских отраслях экономики, но и в сфере обеспечения военной безопасности. Так, только Стратегия развития Арктической зоны и обеспечения национальной безопасности Российской Федерации на период до 2035 года потребует значительного привлечения высококвалифицированных кадров в северные регионы, увеличения состава и структуры воинских частей и подразделений Вооруженных сил, других войск, воинских формирований и органов в Арктической зоне в соответствии с существующим и прогнозируемым характером военных опасностей и военных угроз вплоть до развертывания новых группировок с современным вооружением, военной и специальной техникой, адаптированных к практическим условиям. Одним словом, современные потребности в трудовых ресурсах растут в силу объективного социально-экономического развития России, а темпы их роста не соответствуют имеющимся потребностям.

В этом противоречии автор видит научно-практическую проблему и делает попытку внести свой вклад в ее обоснование и практическое разрешение.

Ретроспективный анализ динамики трудовых ресурсов России позволил автору показать их тесную связь с демографической ситуацией в стране и сделать некоторые прогностические оценки.

Под трудовыми ресурсами автор понимает численность населения страны, способной к трудовой деятельности.

Трудовые ресурсы - это экономически активное и трудоспособное население, которое обладает физическими и духовными способностями к участию в деятельности, полезной для общества.

Трудовые ресурсы страны составляет население 2 категорий:

1) люди трудоспособного возраста (кроме неработающих лиц с инвалидностью и тех, кто получил пенсию на особых условиях);

2) люди за пределами трудоспособного возраста, которые работают (работающие подростки и пенсионеры).

До недавнего времени трудоспособный возраст в России составлял для мужчин 16-60 лет, для женщин - 16-55 лет. Социально-экономические и социально-демографические условия повлияли на установление новых границ трудоспособного возраста. Сегодня в РФ трудоспособный возраст для мужчин составляет 49 лет (16-65 лет), а для женщин - 44 года (16-60 лет).

На 1 января 2020 г. в стране насчитывалось 82,2 млн чел. трудоспособного возраста. Эта цифра нивелируется числом инвалидов - 12,1 млн чел., с учетом которых число трудоспособных граждан составляет всего 70,1 млн чел. С учетом того, что общее население РФ составляет 146,7 млн чел, на долю трудоспособного населения приходится 47,6\%, что является плохим показателем для страны. После повышения пенсионного возраста показатель удалось заметно улучшить: теперь трудоспособное население с учетом инвалидов составляет 80,5 млн чел. (54,8\%). Динамика численности населения трудоспособного возраста представлена в диаграмме на рис. 1. 


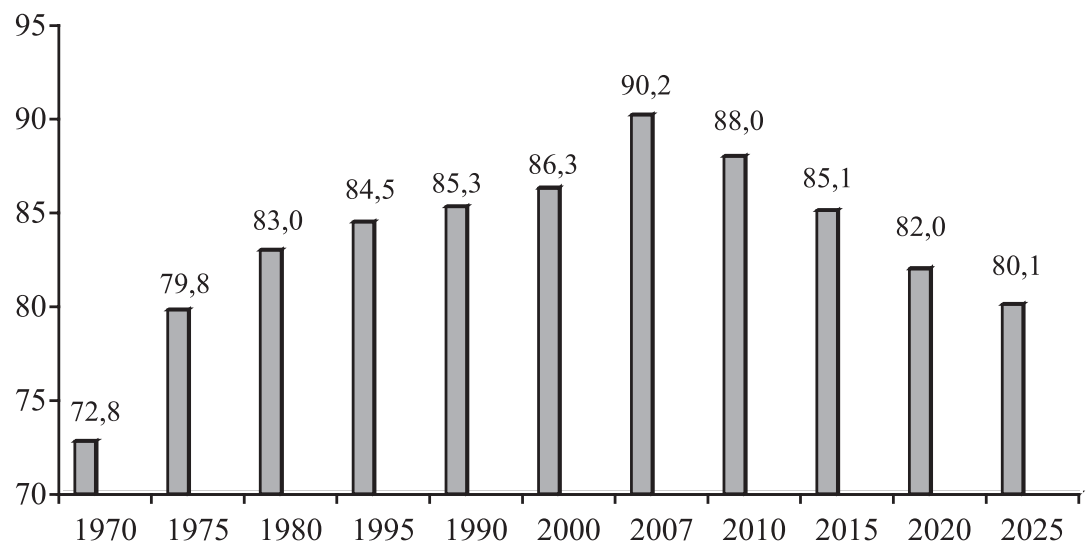

До 2015 г. динамика численности трудоспособного населения России представлена без учета трудоспособного населения Крымского федерального округа.

Источник: https://ru.wikipedia.org/wiki/Трудовые_pесурсы_в_России; http://bs-life. $\mathrm{ru} / \mathrm{rabota} /$ personal/trudosposobniy-vozrast2019.html (проверено 11.09.2021).

Рисунок 1. Динамика численности населения трудоспособного возраста, млн чел.

С 2007 г. в России наметилась тенденция несоответствия численности входящих в трудоспособный возраст численности выходящих из трудоспособного возраста. Замещение поколений стало носить отрицательный характер: -4 700 чел. в 2007 г.; -520,6 тыс. чел. в 2010 г.; -780,2 тыс. чел. в 2015 г.; -366,1 тыс. чел. в 2020 г. ${ }^{1}$ Вырос коэффициент демографической нагрузки, о ем красноречиво свидетельствуют данные табл. 1.

Таблица 1

Коэффициенты демографической нагрузки в России (на 1000 лиц трудоспособного возраста приходится нетрудоспособных на 1 января 2020 г.)

\begin{tabular}{|c|c|c|c|}
\hline \multirow{3}{*}{ Годы } & \multicolumn{3}{|c|}{ Население } \\
\hline & \multirow{2}{*}{$\begin{array}{c}\text { Всего } \\
\text { трудоспособных } \\
\end{array}$} & \multicolumn{2}{|c|}{ В том числе } \\
\hline & & Моложе трудоспособных & Старше трудоспособных \\
\hline 2008 & 582 & 250 & 332 \\
\hline 2009 & 587 & 250 & 337 \\
\hline 2010 & 602 & 255 & 347 \\
\hline 2015 & 694 & 294 & 400 \\
\hline 2020 & 813 & 331 & 476 \\
\hline
\end{tabular}

Источник: Росстат.

Изменив границы трудоспособного возраста, Россия последовала примеру Германии, Японии, Швеции, Франции и США. В Германии, Японии, Швеции

1 rosstat.gov.ru/storage/mediabank/2EfrJGVJ/Rab_sila_2020.pdf 
трудоспособный возраст для мужчин и женщин составляет 65 лет, во Франции - 60,5 лет, в США - 66 лет.

Однако изменение границ трудоспособного возраста - мера разовая, и причины снижения численности трудоспособного населения она не устранила. Главные системные причины падения численности трудовых ресурсов видятся в низкой рождаемости и высокой смертности. В этом мнения экспертов-демографов сходятся (см. рис. 2).
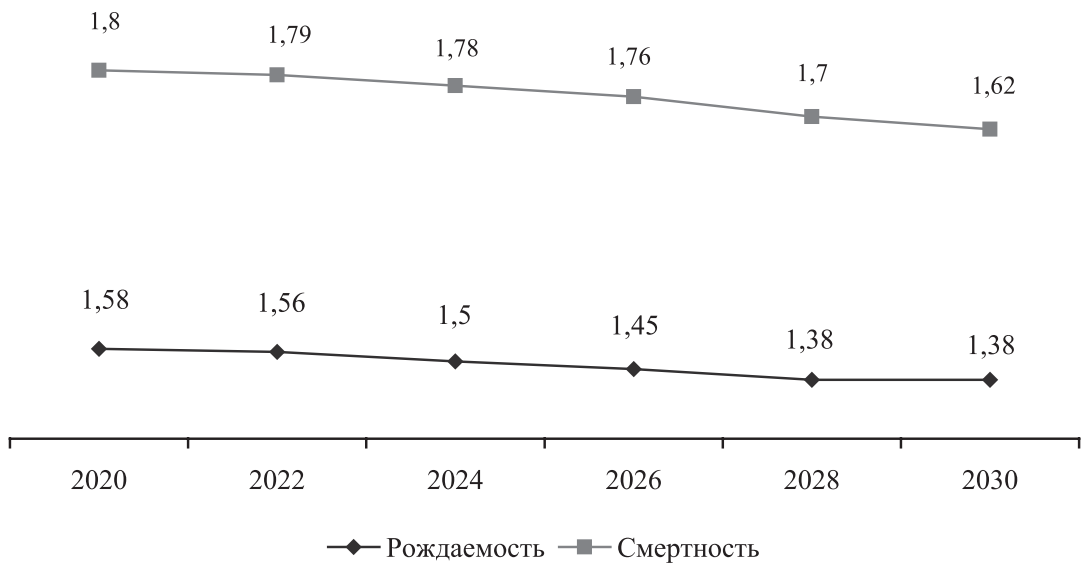

Источник: www.nakanune.ru (проверено 01.11.2020).

Рисунок 2. Рождаемость и смертность в России при увеличении продолжительности жизни до 80 лет (прогноз до 2030 г.), млн чел.

Анализ периодических изданий и данных Росстата позволяет представить демографическую ситуацию в России в динамике и сделать некоторые прогностические расчеты.

К 2025 г. смертность может превысить рождаемость на 450 тыс. чел. (см. рис. 3).

Надо также учесть неравномерность распределения показателей рождаемости и смертности по регионам РФ. Так, естественный прирост населения за 2016-2018 гг. со знаком «минус» наблюдался в 53 субъектах России. Наибольшая естественная убыль населения отмечается в Ленинградской (27,12 тыс.), Московской (11,93 тыс.), Белгородской (16,52 тыс.), Воронежской (35,10 тыс.), Свердловской (12,87 тыс.), Самарской (23,41 тыс.), Ростовской (37,96 тыс.), Липецкой (15,3 тыс.), Курской (19,03 тыс.), Нижегородской (40,76 тыс.), Рязанской (18,34 тыс.), Волгоградской (24,17 тыс.), Кемеровской (27,7 тыс.), Смоленской (18,42 тыс.), Тульской (33,16 тыс.), Кировской (14,3 тыс.), Брянской (19,79 тыс.), Владимирской (24,74 тыс.), Ивановской (18,68 тыс.), Псковской (14,24 тыс.), Орловской (13,85 тыс.), Тверской (27,38 тыс.), Тамбовской (20,784 тыс.) областях, в республиках Крым (19,05 тыс.), Мордовия (11,52 тыс.), Карелия (7,50 тыс.) ${ }^{1}$.

В целом по России в 2016-2018 гг. зафиксировано падение рождаемости, отражающее снижение смертности населения, а также сокращение притока мигрантов при росте оттока граждан РФ. Общий прирост населения за 3 года

1 Рейтинг регионов по демографии подготовлен в 2019 году по заказу РИА Новости агентством РИА рейтинг. Доступ: riareiting.ru/infogrefika/20190423/630123908.html 


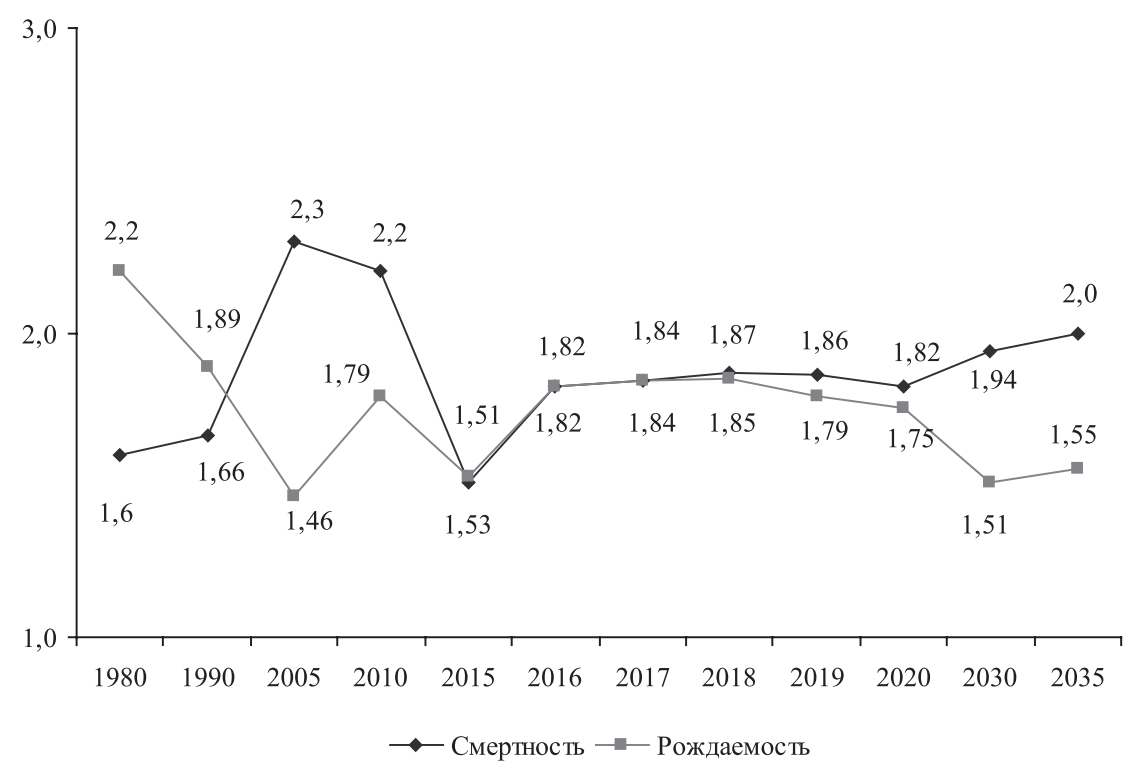

Источник: Росстат (2017-2025 - текущий прогноз).

Рисунок 3. Демографический прогноз Росстата рождаемости и смертности на период до 2025 г., млн чел.

составил 236,02 тыс. чел. $(0,16 \%)$. При этом миграционный прирост составил 598,71 тыс. чел., а естественная убыль - 355,13 тыс. чел. По состоянию на 1 января 2019 г. численность населения (по данным Росстата) составила 146,751 млн чел.

Регионами-лидерами стали г. Севастополь, где численность населения выросла на 6,46\%, Республика Ингушетия $(+5,20 \%)$, Чеченская Республика $(+4,50 \%)$, Тюменская, Ленинградская и Московская обл. $(+4,41 \%,+3,88 \%$ и $+3,84 \%$ соответственно). Более чем на 3,5\% население выросло в 6 регионах, рост населения в диапазоне 3,5\%-1,5\% отмечен в 8 субъектах РФ. Лидерами по миграционному приросту стали регионы с привлекательными рынками труда (Московская обл., Москва, Краснодарский край, Санкт-Петербург, Ленинградская обл).

Многие исследователи считают, что демографическая ситуация в России достигла критического уровня. Главные особенности этой ситуации - значительные масштабы сокращения населения; низкая рождаемость; массовое распространенность однодетных семей, что не обеспечивает воспроизводство населения; продолжающееся старение населения и изменение соотношения между трудоспособным населением и пенсионерами; кризис семьи как высшей национальной ценности; высокий уровень разводов и гражданских браков, не регистрируемых государством.

В любой стране основными критериями оценки демографической ситуации выступают рождаемость и смертность. От рождаемости зависит процесс замещения поколений в обществе. По прогнозу Росстата, население страны будет расти и к 2031 г. достигнет 152,38 млн чел. Однако, по данным демографа И. Белобородова, Россию ожидает очередной спад численности населения в 2025-2030 гг. По его мнению, в результате демографического провала 
население России снизится к 2031 г. до уровня ниже 80 млн чел. [Крикунов, Толстунова, Макарьева 2019]. Это приведет к тому, что Россия не сможет удержать под контролем свою территорию в нынешних границах. По мнению профессора МГУ им. Ломоносова А. Антонова, без возрождения многодетной семьи к 2050 г. в России останется 70 млн чел.

По оценке демографа Ю. Крикунова, если к 2035 г. доля многодетных семей не достигнет половины (сейчас она составляет 7\%), то к концу XXI в. в России останется 80 млн чел. ${ }^{1}$

В результате анализа демографической ситуации в России большинство прогнозов сводится к тому, что к концу XXI в. численность населения России существенно снизится. По прогнозам ООН, ежегодная убыль населения в России до 2050 г. будет составлять 510 тыс. чел. Росстат прогнозирует убыль населения до 2030 г. ежегодно на 485 тыс. чел. В целом, можно заметить, что прогнозы международных организаций и отечественных органов почти полностью совпадают в том, что население России в перспективе будет сокращаться и, как следствие, будет продолжаться процесс снижения уровня трудовых ресурсов страны.

Следует заметить, что население советской России ежегодно росло, и потребности в трудовых ресурсах были почти повсеместно удовлетворены, т.е. наблюдалось соответствие между потребностями экономики в трудовых ресурсах и возможностями страны обеспечивать эти потребности.

Численность населения РСФСР к моменту распада СССР составляла 149 млн чел. К 1986 г. в РСФСР родились 2 млн 486 тыс. чел., умерли 1 млн 498 тыс. чел. Естественный прирост составил 988 тыс. чел. С середины 1991 г. впервые за последние столетия смертность в России превысила рождаемость. Так, в 1994 г. родились 1 млн 420 тыс. россиян, а умерли 3 млн 300 тыс. (на 880 тыс. больше родившихся). В процентах эти показатели составили: рождаемость $-0,93 \%$, смертность - 1,5\%; разница между ними составляет $-0,57 \%$. Россия стала ежегодно терять почти по 1 млн чел. [Возжеников, Стрельченко 2009]. Особенно катастрофической оказалась ситуация в так называемых исконно русских регионах. Например, в Псковской обл. на 6434 родившихся в 1995 г. пришлось 35248 умерших (убыль - 21966 чел.).

В пореформенной России не произошел поворот к повышению рождаемости. Семья как ячейка общества не стала главной национальной ценностью. Еще совсем недавно (в историческом измерении) в России господствовала многопоколенная патриархальная семья с традиционными моральными устоями. В XX-XXI вв. наступило резкое разрушение естественных традиционных связей и семейных ценностей с высокими традиционными моральными устоями. Произошло разрушение естественных традиционных связей между людьми - общинных, родовых. По показателю распада браков Россия превзошла к 1994 г. все бывшие республики СССР, кроме Латвии, и опередила практически все страны мира, уступая лишь США².

Таким образом, можно заключить, что основными демографическими проблемами для России являются высокая смертность, низкая рождаемость и естественная убыль населения на протяжении последних 20 лет. Необходимы дополнительные государственные меры по совершенствованию демографической политики, включая и семейную политику.

На фоне демографического кризиса происходит естественное сокращение трудоспособного населения страны (см. рис. 4).

\footnotetext{
1 arigus.tv/interview/detail.php?ID $=67014 \&$ sphrase_id $=6007603$

2 scitnceforum.ru/2019/article/2018013787
} 


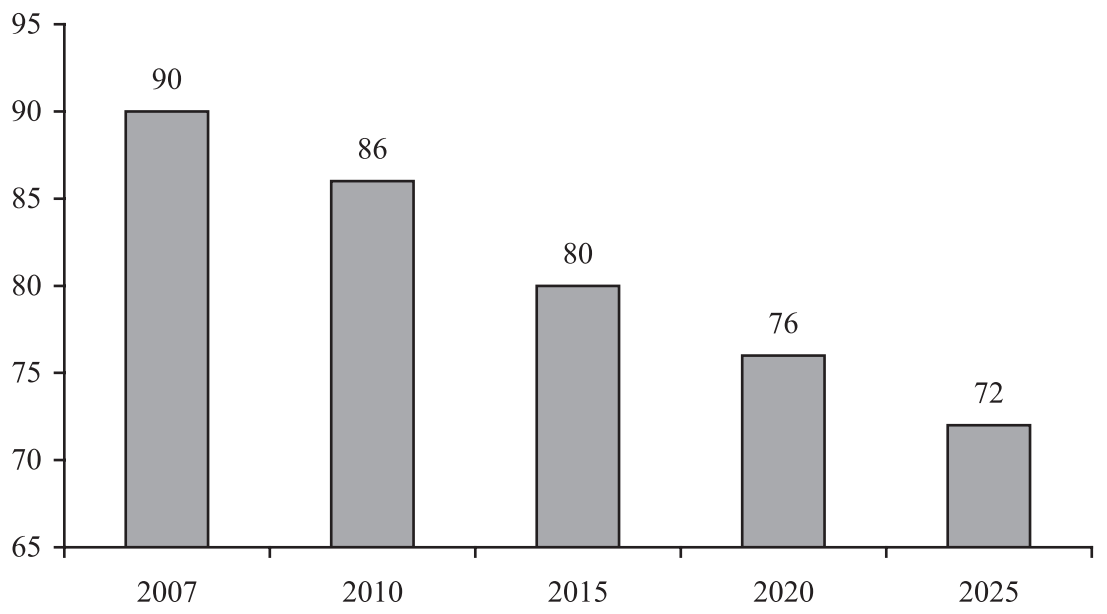

Источник: Росстат.

Рисунок 3. Динамика трудовых ресурсов в Российской Федерации (состояние и прогноз до 2025 года), млн чел.

Численность трудоспособного населения в России с 2007 по 2020 г. уменьшилась на 10,3 млн чел. ${ }^{\text {, }}$, а потребности экономики в трудовых ресурсах выросли.

В 2019 г. темпы снижения численности трудовых ресурсов ускорились: в I квартале они сократились почти на 800 тыс. чел. по сравнению с I кварталом 2018 г. В результате число экономически активных граждан (без учета Республики Крым и г. Севастополя) вернулось к уровню 2005 г. Можно предположить, что в настоящее время достигнут предел экономической активности для населения в основных трудовых возрастах. Дальнейший рост возможен главным образом лишь за счет активного вовлечения в рынок труда населения старшего возраста.

В оперативной оценке Росстата 4 июня 2019 г. отмечалось, что за минувшие 12 месяцев численность трудовых ресурсов в стране уменьшилась на 1 млн 64 тыс. чел. ${ }^{2}$ Столь резкого сокращения трудовых ресурсов в России в XXI в. не наблюдалось. Как следует из данных Росстата, экономика теряет в среднем ежемесячно по 80-90 тыс. рабочих.

Начало тенденции снижения численности трудовых ресурсов было положено в 2016 г., но до 2019 г. это снижение было медленным.

Главная причина, из-за которой происходит сокращение численности трудовых ресурсов в России, вполне объяснима: сокращение численности россиян в границах трудоспособного возраста из-за последствий так называемой демографической ямы начала 90-х гг. XX в. Начиная с 2006 г. число трудоспособных граждан сокращалось ежегодно на 9\%, и на начало 2020 г., как уже было замечено, эта цифра составляет 52 млн чел. Если бы уровень экономической активности на фоне такой отрицательной динамики численности трудоспособного населения не менялся, то, по оценке экономиста РАНХиГС В. Ляток, пока-

\footnotetext{
1 Численность населения. Доступ: https://xn----8sbncanfseqabeh4bfdo0g7e4c.xn--plai/

2 Почему количество трудоспособного населения в России сокращается, а безработицы нет? Доступ: zen.yandex.ru/media/mosobr/pochemu-kolichestvo-trudosposobnogo-naseleniiav-rossii-sokrascaetsia-a-bezrabotica-net-5cf4f0ea6d847900afdd514a
} 
затель рабочей силы сократился бы еще больше. При этом демографические изменения традиционно компенсировались дополнительным вовлечением населения в трудовые отношения.

В целом, по оценке экономистов РАНХиГС, совокупный уровень экономической активности населения за период с 2000 по 2018 г. увеличился на 3,8\%. Однако динамика показателя весьма различалась по возрастным группам.

Так, в возрастной группе 15-19 и 20-24 лет этот показатель сократился с $18,4 \%$ и 68,7\% в 2000 г. до 7,7\% и 56,4\% в 2018 г. соответственно. В остальных возрастных группах уровень экономической активности оказался через 18 лет выше как минимум на 2\%. В максимальных значениях он вырос в возрастной группе 55-59 лет: до 2018 г. он составлял 52,8\%, а на 1 января 2019 г. - 66,5\%.

Как отмечают аналитики, пик экономической активности в России в целом «постарел». Раньше этот пик относили к возрастной группе 35-39 лет (90,9\%), а сегодня пик приходится на 40-44-летних россиян (91\%). В основном на росте экономической активности населения отразилось небольшое увеличение ее уровня в зрелом и значительное - в пожилом возрасте. Показатели по данным категориям граждан также снижаются как для пожилых, так и для молодежи.

В среднесрочной перспективе на численность трудовых ресурсов в России будет влиять «медицинская проблема». На общем собрании членов РАН 15 ноября 2019 г. директор Института социально-экономических проблем народонаселения РАН В. Локосов в своем докладе отметил, что еще как минимум 10 лет население России будет уменьшаться. Также в докладе говорилось, что параллельно процессу сокращения народонаселения осложняется ситуация со здоровьем детей. «Число абсолютно здоровых детей до 3 лет снизилось с $49 \%$ до 12\%. Ухудшилось репродуктивное здоровье населения. По данным Всемирной организации здравоохранения, критический порог $-15 \%$ бездетных семей. Наше общество перешло эту черту в 2016 году, и сейчас более $17 \%$ наших семей являются бесплодными. По данным Минздрава РФ, до $70 \%$ смертей мужчин трудоспособного возраста так или иначе связано с употреблением алкоголя» ${ }^{1}$.

Можно выделить пять главных факторов, влияющих на демографическую ситуацию в России и процесс развития трудовых ресурсов.

1. Сокращение численности трудоспособного населения. Есть разные прогнозы, но все эксперты сходятся в том, что доля нетрудоспособного населения будет увеличиваться и к 2030 г. достигнет $30 \% 2$.

2. Дальнейшее старение населения, которое неминуемо приведет к увеличению социальных расходов.

3. Из-за снижения рождаемости и уровня здоровья населения резко сократился призывной контингент Вооруженных сил РФ. В 2020-х гг. число молодых людей, подлежащих призыву, будет в 2 раза меньше по сравнению с периодом 15-летней давности. Ежегодно до $20 \%$ призывников оказываются непригодными к службе в армии по состоянию здоровья.

4. Изменения этнической структуры населения из-за трудовых мигрантов ${ }^{3}$. У России огромные возможности привлечения мигрантов из других стран, но нужно к этому относиться осторожно, т.к. прямые выгоды могут обернуться в стратегическом плане большими проблемами.

\footnotetext{
1 Локосов В. Медицинская проблема становится социальной. Доступ: http://mosday.ru/ news/item.php?2059544\&tags=crime (проверено 11.09.2021).

2 Все прогнозы сделаны без учета повышения пенсионного возраста для женщин и мужчин.

3 Анализировать данную тенденцию сложно из-за отмены с 2007 г. учета национальности при сборе информации.
} 
5. Отток населения с Дальнего Востока, из Сибири и ряда других регионов. Сибири и Дальнему Востоку уделяется должно внимание, но отток идет из субъектов Центрального и Северо-Западного федеральных округов.

Для преодоления сложившейся кризисной демографической ситуации требуется комплекс мер. И главная из них - укрепление социальной ответственности государства перед обществом.

Последние 30 лет население России стало больше платить за медицинские услуги. По данным Института социально-экономических проблем народонаселения РАН, доля оплаты счетов за медицинские услуги из личных средств увеличилась до 40\%. Если государство снова возьмет на себя часть обязательств в системе здравоохранения и образования, это позитивно отразится на демографическом процессе и процессе формирования трудовых ресурсов.

Главное препятствие для рождения детей - материальные и жилищные трудности [Возжеников, Соловьева 2008]. Чтобы преодолеть демографический кризис в России, необходимо улучшать качество жизни. По оценке Минтруда РФ, около $80 \%$ семей сегодня находятся за чертой бедности ${ }^{1}$.

Демографическую ситуацию также способно улучшить возвращение граждан к традиционным семейным ценностям.

Многодетность - одна из таких ценностей. Социологические исследования утверждают, что именно ценностная ориентация находится на первом месте, когда человек определяет демографическое поведение. Это исследование подтверждает демографическое поведение жителей Северного Кавказа и Средней Азии.

В данной связи необходима также модернизация экономики на инновационной основе. Повышение производительности труда, роботизация производства серьезно отразятся на рынке труда и возможности демографического развития нашей страны. Переход к цифровой экономике не должен вести к появлению «лишних людей» и упразднению целой линейки трудовых специальностей.

Серьезной проблемой в формировании трудовых ресурсов России являются изменения в возрастной пирамиде страны, приводящие к старению населения и, как следствие, к сокращению наличных трудовых ресурсов в среднесрочной перспективе. Негативные последствия этого явления пока сглаживаются миграционным притоком и работающими инвалидами.

Государственная политика в сфере наращивания трудовых ресурсов должна решить ряд задач демографической направленности. Среди них - сокращение и укрепление здоровья населения, увеличение продолжительности активной жизни, создание условий и формирование мотивации для ведения здорового образа жизни, существенное снижение уровня заболеваемости социально значимыми болезнями, улучшение качества жизни больных, страдающих хроническими заболеваниями; повышение уровня рождаемости за счет рождения в семьях второго ребенка и последующих детей; укрепление института семьи, возрождение и сохранение традиционных духовно-нравственных семейных отношений.

Сложившаяся в России демографическая ситуация показывает, что решить проблему обеспеченности страны трудовыми ресурсами государственными мерами только экономического характера невозможно. Необходимы комплексные подходы, смена самой парадигмы регулирования демографических процессов. Необходимо усиливать воздействие аксиологических факторов в регулировании воспроизводства населения в целях повышения рождаемости.

1 ria.ru/20191117/156985696/html 
Проблема повышения рождаемости - это проблема формирования моральных ценностей, где в центре находится многодетная семья. Сегодня у большинства населения система ценностей, по своей сути, антисемейна. Любая государственная политика материального стимулирования рождаемости обречена на провал без включения механизма морально-нравственных семейных ценностей.

Как и во многих странах мира, демографический кризис в России вызван не столько экономическими, сколько моральными проблемами и упущениями в формировании национальной системы ценностей. Индивидуализм как современная альтернатива советскому коллективизму ведет к росту числа гражданских браков и отказу от деторождения, разводам, нежеланию заботиться о детях и родителях. Велика роль в вопросах нравственного воспитания образовательных учреждений, СМИ. Школьные программы и публикации СМИ, затрагивающие вопросы семьи и пола, должны повествовать о святости и чистоте полноценной семейной жизни, учить традиционным нравственным законам поведения в браке.

Несмотря на рассмотренные проблемы, есть и хорошие тенденции, позволяющие смотреть в будущее с осторожным оптимизмом. Росстат указывает на сокращение смертности в России от убийств, самоубийств, алкогольных и наркотических отравлений. Для исправления ситуации надо развивать положительные тенденции, объединяя усилия ученых, интегрировать демографические и социально-экономические меры.

\title{
Список литературы
}

Возжеников А.В., Соловьева О.Н. 2008. Семейная политика как социальная проблема государства. - Государственная служба. № 3. С. 102-104.

Возжеников А.В., Стрельченко В. 2009. Региональная асимметрия и угрозы целостности страны. - Государственная служба. № 1. С. 45-50.

Крикунов Е.А., Толстунова Г.П., Макарьева Е.А. 2019. Демографические проблемы современной России. - Материалы ХI Международной студенческой научной конференции. 2019. Доступ: https://scienceforum.ru/2019/ article/2018013787 (проверено 11.09.2021).

\section{LABOR RESOURCES OF RUSSIA IN THE MIRROR OF THE DEMOGRAPHIC SITUATION}

\begin{abstract}
The article examines the problems that hinder the development of labor resources in the context of the demographic situation. The author analyzes the forecasts and dynamics of the population of the country; formulates proposals for enhancing the state policy on improving the demographic situation and increasing labor resources in the Russian Federation.
\end{abstract}

Keywords: labor resources, demographic policy, family, birth rate, mortality, demographic crisis, population size, age groups 